Jan Svennevig* and Anne Marie Dalby Landmark

\title{
Accounting for forgetfulness in dementia interaction
}

https://doi.org/10.1515/lingvan-2018-0021

Received May 7, 2018; accepted December 13, 2018

\begin{abstract}
The article identifies and describes conversational practices used by persons with dementia and their interlocutors to account for the former's lack of knowledge in cases where information about their personal experiences is made relevant and expectable at a specific point in a conversation. First, they may seek to normalize the lack of knowledge by claiming that it would be difficult for anyone to know or remember the information in question. Second, they may exceptionalize it by claiming that their cognitive or communicative impairment incidentally and temporarily disables them from accessing the information. Finally, they may justify their failure to provide information by claiming that it is not important, relevant or expectable that they should know. Such accounts dissociate the social character from the forgetfulness and thus constitute an attempt to avoid the loss of face associated with not remembering personal experiences. By specifying these conversational accounting practices, the study thus adds to existing knowledge on how participants handle the social sensitivity of typical dementia symptoms.
\end{abstract}

Keywords: dementia; Conversation Analysis; accounts; forgetfulness; negative epistemics.

\section{Introduction}

Sharing memories and talking about the past is an important part of sociable conversation, especially among elderly people (Underwood 2010). However, dementia may lead to memory loss, and persons with dementia may appear forgetful to their interlocutors. This is not just a cognitive problem of access to knowledge, but just as much a social problem of interpersonal relations and self-esteem, since not remembering personal experiences is associated with losing face vis-à-vis one's interlocutors (Guendozi and Pate 2014). For instance, being unable to provide information about personal relationships, such as family and friends, may constitute a sensitive situation in that the lack of knowledge may be interpreted as a lack of involvement or interest in the persons involved. Thus, in this article we seek to investigate what persons with dementia and their interlocutors do to avoid the social stigma of appearing forgetful about personal background knowledge. More specifically, we ask:

How do persons with dementia and their interlocutors account for lack of knowledge in cases where reporting personal experiences is made relevant and expectable in conversation?

In order to answer this question, we need to clarify what we mean by concepts such as knowledge and accounts.

\section{Knowledge and accountability}

Rights and access to knowledge are socially distributed and normatively organized (Stivers et al. 2011). This social organization of knowledge and its consequences for conversational interaction are studied

\footnotetext{
*Corresponding author: Jan Svennevig, MultiLing - Center for MultiLingualism in Society across the Lifespan, University of Oslo, Oslo, Norway, E-mail: jan.svennevig@iln.uio.no

Anne Marie Dalby Landmark: MultiLing - Center for MultiLingualism in Society across the Lifespan, University of Oslo, Oslo, Norway
} 
under the heading of social epistemics (Heritage 2012). A central finding in this tradition is that people have different rights and obligations concerning different types of knowledge. More specifically, people are considered to have primary rights to first-hand knowledge, that is, knowledge based on personal experience (Pomerantz 1980; Raymond and Heritage 2006). This gives them epistemic authority to make claims about and assess events and phenomena within their personal sphere, but it also involves obligations to have access to such information and being able to provide evidence of it when required. People are thus held accountable for knowing certain things and failing to provide this information may consequently be perceived as socially problematic. They may thus be expected to account for such breaches of expectations.

The theoretical concept account was introduced by Scott and Lyman (1968) to designate "a statement made by a social actor to explain unanticipated or untoward behavior" (p. 46). One type is excuses, by which "one admits that the act in question is bad, wrong, or inappropriate but denies full responsibility", and another is justifications, by which "one accepts responsibility for the act in question, but denies the pejorative quality associated with it” (p. 47).

In Conversation Analysis, the target of accounts has been broadened to include potential breaches of any norm underlying conversational practices or social actions, so-called relevance rules (Heritage 1988). In Robinson's (2016: 15) words:

[...] an account is an attempt by one interlocutor to modify (e.g. change, explain, justify, clarify, interpret, rationalize, (re)characterize, etc.), either prospectively or retrospectively, other interlocutors' understandings or assessments of conduct-in-interaction in terms of its "possible" breach of relevance rules [...].

To give an example, questions create the conditional relevance of an answer (Schegloff and Sacks 1973), and a failure to provide one will make the interlocutor accountable. Thus, when interlocutors are not able or willing to produce an answer to a question (such as for instance "why did your family move to Norway?"), they will generally provide an account, either an excuse ("I don't know, they never told me") or a justification ("It's a long story, I won't bother you with the details”).

\section{Forgetfulness in interaction}

Recently, several studies have addressed the topic of how and when social actors claim not to know or remember something. In a recent special issue, so-called 'negative epistemic constructions' (e.g. “I don't know/remember/understand") have been documented across a variety of languages (Lindström et al. 2016) and were found to serve a range of interactional functions within two broad usage types.

First, negative epistemic constructions can be used in a literal sense, as disclaimers of knowledge, that is, epistemic access. These tend to be produced in syntactically and morpho-phonologically full forms. Second, they may be used in a less literal sense, rather serving other pragmatic and interactional functions. These were commonly produced in reduced grammatical forms (e.g. "dunno" in English) (Lindström et al. 2016). One such discursive function is prefatory hedging or approximation, downgrading the speaker's epistemic stance with regard to the subsequent claim (e.g. Weatherall 2011; Pekarek Doehler 2016). Another function in turn-initial position is to project a non-fitted response (e.g. Pekarek Doehler 2016). Furthermore, "I don't know"-constructions can convey a disaffiliative stance, such as criticism (Deppermann 2011) or resistance (Hutchby 2002). In turn-final position it may serve to mark the answer to a question as not fulfilling the conditional relevance set up by the question (Pekarek Doehler 2016). Importantly for the present study, “I don't know"-responses are generally treated as socially problematic, as they fail to provide the information requested and can thus be considered uncooperative. Consequently, they are regularly accompanied by accounts, preempting such negative interpretations. Accordingly, stand-alone "I don't know"responses can imply that the problem lies with the question or express resistance towards it (Keevallik 2011). 
Turning to studies on forgetfulness more specifically, these have mainly focused on claims of not remembering that are doing jobs other than conveying a lack of recollection. They can be used as cooperative moves: as a participatory resource, e.g. to encourage participation from a co-teller (Goodwin 1987; Laury and Helasvuo 2016), or to display modesty (Tao 2016). More confrontational moves have also been documented, such as to avoid accountability or to display resistance (Muntigl and Choi 2010). In sum, “I don’t know/remember"-types of claims have been found to accomplish a wide range of interactive functions, not necessarily oriented to cognitive limitations.

However, a few studies have investigated expressions of lack of knowledge in persons with dementia. For instance, Stickle (2015) found that persons with dementia used "I don't know"-utterances more frequently than non-impaired persons. But interestingly, they used such utterances in "much the same way as non-impaired persons: to display epistemic stance but also to manage sequences of talk (i.e. closing or initiating topics) and to manage preference (e.g., disagreeing with co-participants).” Also, persons with dementia used "I don't know"-utterances in first pair parts to initiate what the author calls "wondering" actions. Finally, Nilsson (2017) has investigated couples in which one of the spouses has dementia. The author shows that the spouses may have different expectations in what the spouse with dementia should remember, and that this may cause interactional problems. The healthy spouse may use fishing techniques as a way of eliciting the missing information. However, such fishing techniques were rarely successful, but rather contributed to foregrounding the cognitive impairment and causing embarrassment in the spouse with dementia.

With the notable exception of Nilsson (2017), there is a remarkable lack of research on the social consequences of forgetfulness in relation to cognitive deficits. Furthermore, previous research has not distinguished between various types of knowledge and the inherent rights and obligations associated with them. The present study thus aims to contribute to filling this gap in research. By doing so, it contributes both to the understanding of how dementia symptoms are handled in interaction and to specifying practices used for disclaiming knowledge (negative epistemics).

\section{Data and method}

Data for this study is video-recorded interactions between persons with dementia and health professionals, relatives and researchers. Some are naturally occurring interactions, such as home help visits and dinner table conversations, others are interviews and conversations with researchers, such as biographical interviews and small talk. The participants are elderly persons with a dementia diagnosis, recruited from a memory clinic at a hospital in Norway and from various day centers for elderly people. Names of persons and places are anonymized. The data were collected as part of a project on dementia and multilingualism, so the participants are all multilingual. The conversations are thus not just conducted in Norwegian but also in a range of different languages, such as English, Tamil, French and Punjabi. In addition to the conversational data, the project includes linguistic and cognitive testing of the participants (see Lind et al. 2018 for more information).

The method for analysis is Conversation Analysis (CA) (Heritage 1984b; Sidnell and Stivers 2013). The analysis was conducted by establishing a collection of instances where the persons with dementia produced negative epistemic claims. A subgroup of these contained accounts for the lack of knowledge, and the accounts were further analyzed as for what sorts of reasons were invoked. In some of the accounts, the speakers attributed the responsibility for not remembering to themselves and their own shortcomings, whereas in others they attributed the responsibility to external factors, such as unrealistic expectations by the interlocutor (not-at-fault accounts). These coincided with the categories identified by Scott and Lyman (1968) as excuses and justifications.

Among the accounts that contained excuses, a further subdivision emerged as to whether they referred to 'normal' or common causes for the lack of knowledge, or invoked the dementia condition as a cause, explicitly 
or implicitly. We label the former category normalizing accounts, as the speakers present the epistemic problem as a problem that could happen to anyone. We label the latter exceptionalizing accounts, as the speakers present the memory problem as not representative of their normal state.

\section{Analysis}

This section presents typical cases of the types of accounts found in the data and describes their general features. It starts by normalizing and exceptionalizing accounts, which are forms of excuses, and then proceeds to justifications. Finally, we will consider a case where the lack of knowledge is not accounted for by the person with dementia.

\subsection{Normalizing accounts}

Normalizing accounts attribute problems of epistemic access to common causes of memory failure, thereby not invoking the dementia condition. The first excerpt (1) is from a coffee table conversation at a day center, involving four persons with dementia, a nurse (Liv) and one of the researchers (Jan). One of the persons with dementia, Anne, has been telling that they used to have a summer house in Italy. Liv asks where the house was:

\section{Excerpt (1) Anne}

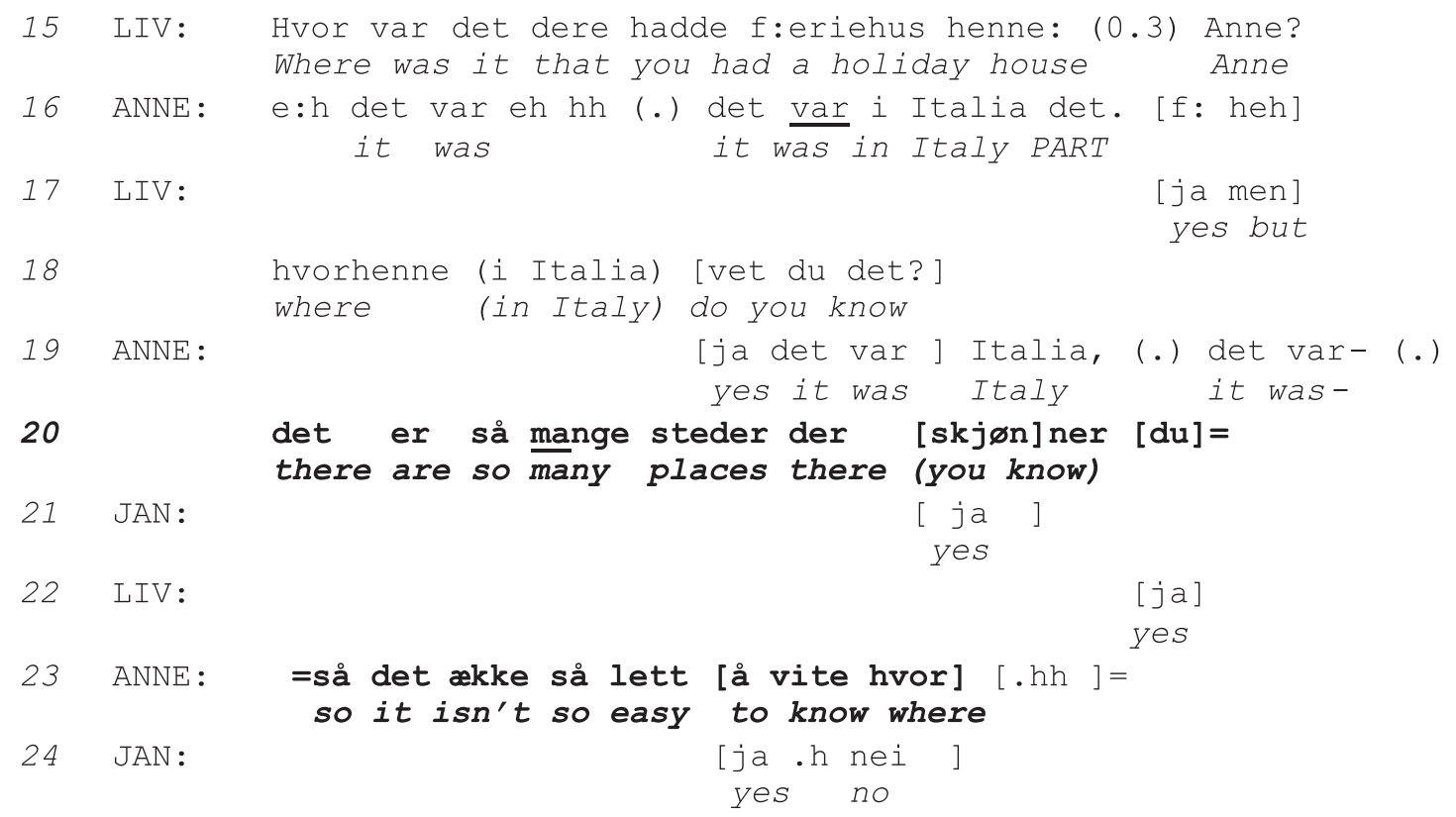

Anne's first answer is treated by Liv as insufficient in that she reinitiates the question, specifying it further (line 18). The question is also interesting in that Liv appends a tag question whether Anne knows ('do you know?'), thus orienting to potential problems of epistemic access. Anne initiates two type-conforming answer introductions but aborts the last one mid-course and instead produces an account for not being able to answer (lines 20, 23). The account invokes an external problem, namely the number of places (and consequently, place names) in Italy. The problem is thus presented as a general problem, not just a problem for her. This excuse relieves her of the responsibility of knowing by claiming that it would be a problem to anyone, thereby normalizing the problem of epistemic access. By using such an account, she seeks to maintain an impression of being in character and being like everyone else - in Sacks' words, "doing being ordinary" (Sacks 1984). 
And her interlocutors contribute to co-constructing this impression by accepting her account (lines 21, 22 and 24), in spite of its obvious lack of common sense logic and likelihood.

Accounts are not just produced by the persons displaying epistemic problems themselves. On some occasions, their interlocutors come in with accounts on their behalf. Consider excerpt (2), in which Tove, a nurse in a residential facility for persons with dementia, talks to a resident, Sven, about a family photo he has picked up from his shelf.

\section{Excerpt (2) Sven}

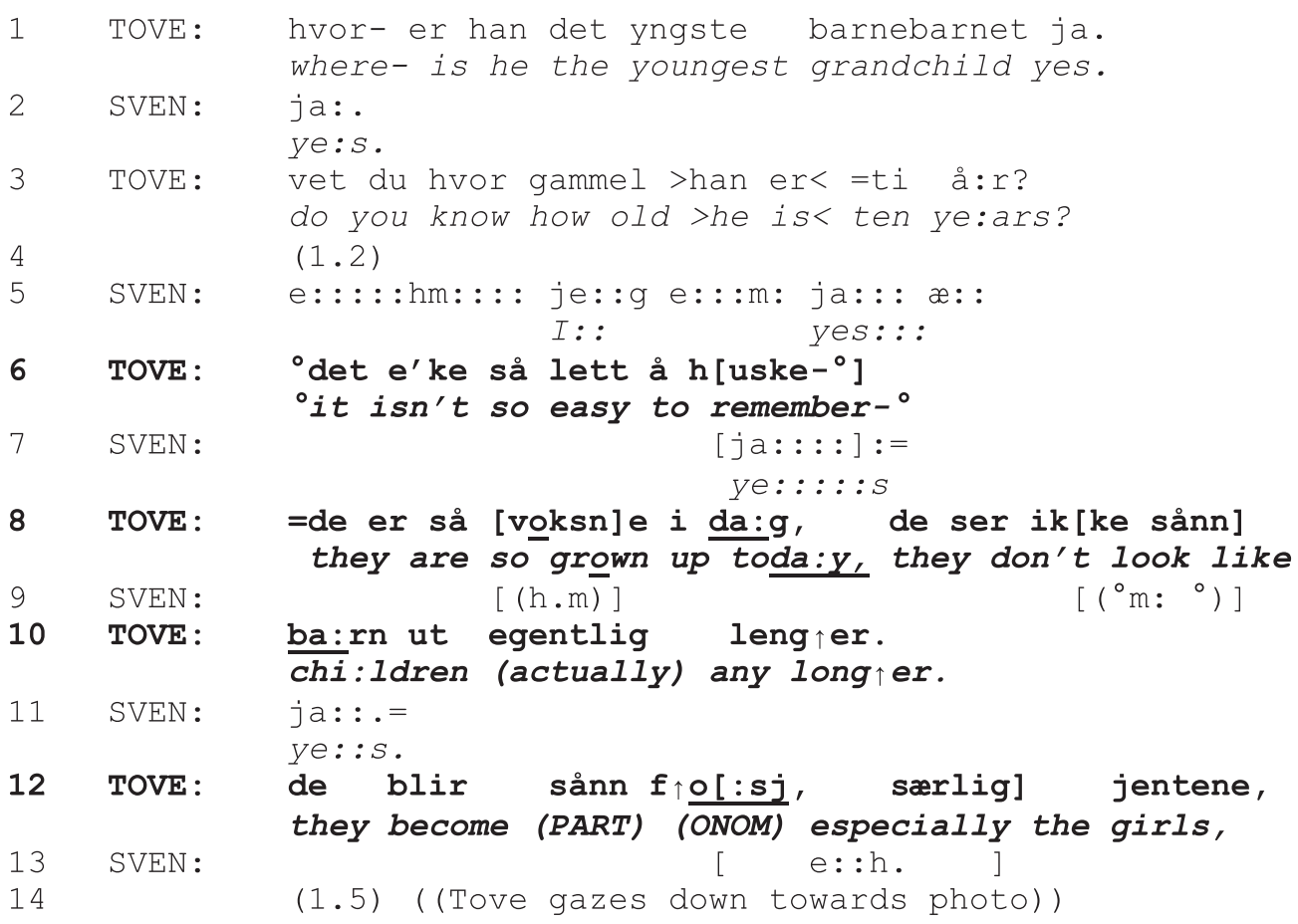

In this part of the conversation, Tove poses a series of questions about the people in the picture. In line 3, she enquires about the age of Sven's youngest grandchild. Here, the question preface 'do you know?' from the outset takes into account the possibility that Sven might not have epistemic access to the information requested. Grammatically, this design does not presuppose the recipient's knowledge, and thus reduces the expectation of a knowing response. She also alleviates the burden of finding an answer by adding a candidate answer in the form of a 'guess' (“ten years?") (Svennevig 2013). This is latched on to the question, thus turning it into a simple request for confirmation. The following 1.2 second pause and the elongated pre-beginning hesitation marker (lines 4-5) indicate problems of responding. In the end, Sven produces a prolonged "I::", which might be heard as the beginning of an “I don't know"-response. This aborted turn initiation might be what Tove picks up on when she comes in with an account on his behalf in line 6. Her account presents the problem as a general problem of remembering such things. She elaborates further on this in lines 8 and 10, presenting the reason as relating to the appearance of children today (as opposed to earlier times). This excuse for not remembering thus attributes the problem to external reasons rather than to Sven's memory. By expanding the topic even further in line 12, and vividly demonstrating the speed of growth by an onomatopoetic expression ("f $\uparrow \mathrm{o:sj}$,"), Tove portrays herself as someone with firsthand experience, thereby implicitly claiming that this is a problem for her as well (Heritage 2011). This example thus shows how interlocutors may attend to, and work to mitigate, the potential delicacy of the persons with dementia's lack of epistemic access, both in the formulation of questions and in providing accounts for lacking answers on their behalf. 


\subsection{Exceptionalizing accounts}

The second category of accounts invokes explicitly or implicitly the dementia condition as an explanation for the problem of epistemic access. In excerpt (3), from an autobiographical interview conducted by a researcher (Hanne) in English, the person with dementia, Laura, is telling about her childhood:

\section{Excerpt (3) Laura}

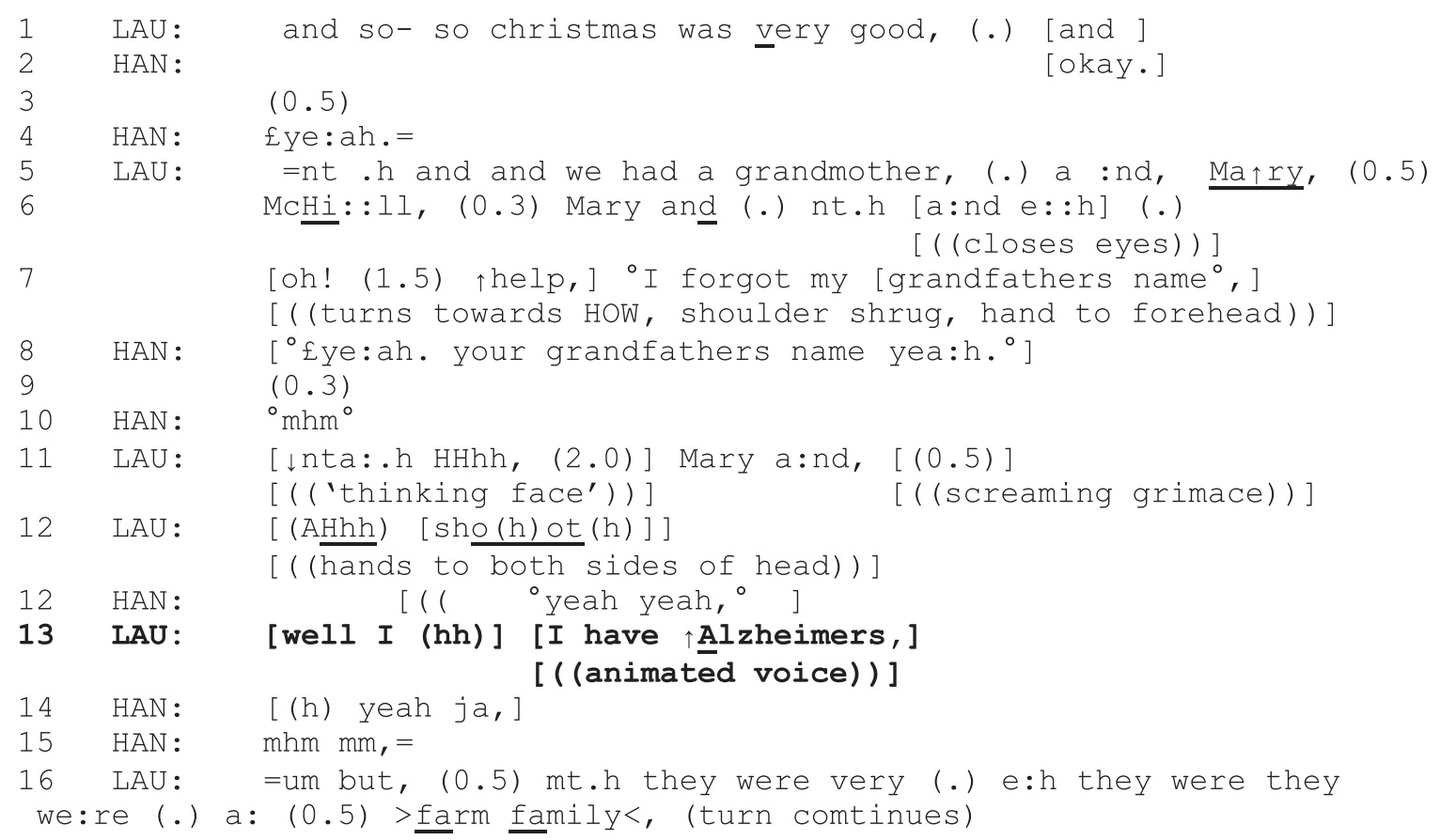

Having presented the name of her grandmother in lines 5-6, Laura initiates a conjoined construction that projects a second name ("Mary and"). However, she displays problems in continuing the construction by producing fillers (eh), repeating the construction initiated ("and", "Mary and"), elongating the words produced and by setting up a 'thinking face'. She also produces a metacomment revealing the nature of the problem and the target word being searched for ("I forgot my grandfather's name"). These are typical features of word searches, whereby speakers delay the production of a word being searched for (Goodwin and Goodwin 1986). She also repeatedly expresses exasperation at not finding the word searched for, both verbally ("oh", "help", "ah shoot") and gesturally (screaming grimace, hands to both sides of the head). After a long period of time searching for the name without success, she produces the account "well I have Alzheimer's" (line 13). This can be categorized as an excuse, reducing her responsibility for the forgetfulness by attributing it to the illness. The account thus rationalizes her forgetfulness, and the expressions of exasperation convey that she treats the problem as exceptional. Thereby, these features contribute to maintaining an impression of her as a person who is temporarily 'out of character' (Goffman 1959) and aware of the expectation that she ought to have epistemic access to this type of experiential knowledge. Thereby, the account may be considered as 'exceptionalizing' the problem.

In other cases, the reference to the illness is less explicit and instead invoked more indirectly in accounting for the lack of knowledge. In the next excerpt, from the same conversation as (1) above, the person with dementia (Anne) has been telling the researcher (Jan) that she had lived in Italy for a period of time and that she spoke Italian. Jan reports having learned some Italian himself, and in the extract below, he is searching for the word for 'cheers' in Italian. 


\section{Excerpt (4) Anne}

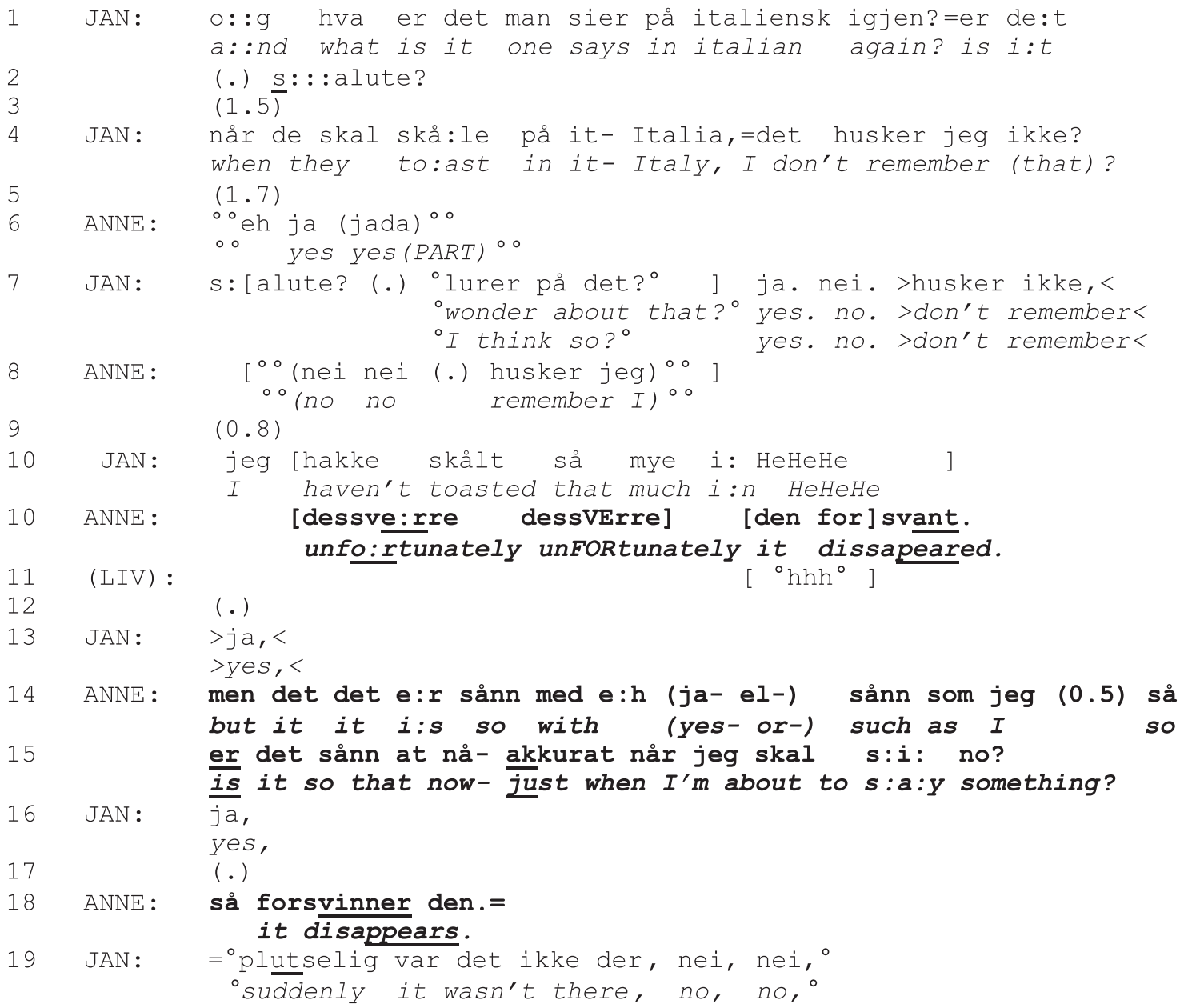

Jan formats his word search as questions. Such questions may be self-directed, but in this case, where Anne is established as a speaker of Italian, they may well be heard as appeals to her for suggestions (line 1) and for confirmation of the candidate proposed in line 2 (Goodwin and Goodwin 1986). Receiving no response from Anne, he repeatedly reinitiates the search in the following lines. Finally, he exits the search activity by claiming not to remember (line 7) (Keevallik 2016) and accounts for the lack of knowledge (line 10). Anne had produced a response in line 8 in soft voice, seemingly indicating that she does not remember. But at this point, she comes in with a more substantial response in the form of an account for not answering, namely that "it disappeared" (line 10). This account may seem to invoke a situation where she incidentally and temporarily lost the grasp of a word. However, she expands her account by relating the incident to a more general problem of words "disappearing" when she is about to say something. Jan contributes to co-constructing this account by paraphrasing her description, thus displaying his understanding of the problem (line 19). Without mentioning the dementia condition explicitly, Anne here alludes to it by presenting it as a speech production problem. In combination with the expression of regret ("unfortunately"), the account presents the problem as exceptional and claims that she would normally be able to provide the word. By excusing her lack of knowledge, she displays selfawareness of the problem and claims normality and rationality apart from this specific word-finding problem.

\subsection{Justifications as accounts}

Some accounts reduce or deny the problematic character of not knowing. A typical form is claiming that knowing or remembering is not important. In the following extract (5), the person with dementia, Koki, is in the kitchen talking to his home help nurse, Amina. Prior to the extract, he has been inspecting a tube of 
adhesive for his dental prosthesis and has asked Amina if it has "come recently". She responded that "that might be", and in the excerpt, she elaborates on the provenance of the tube.

\section{Excerpt (5) Koki}

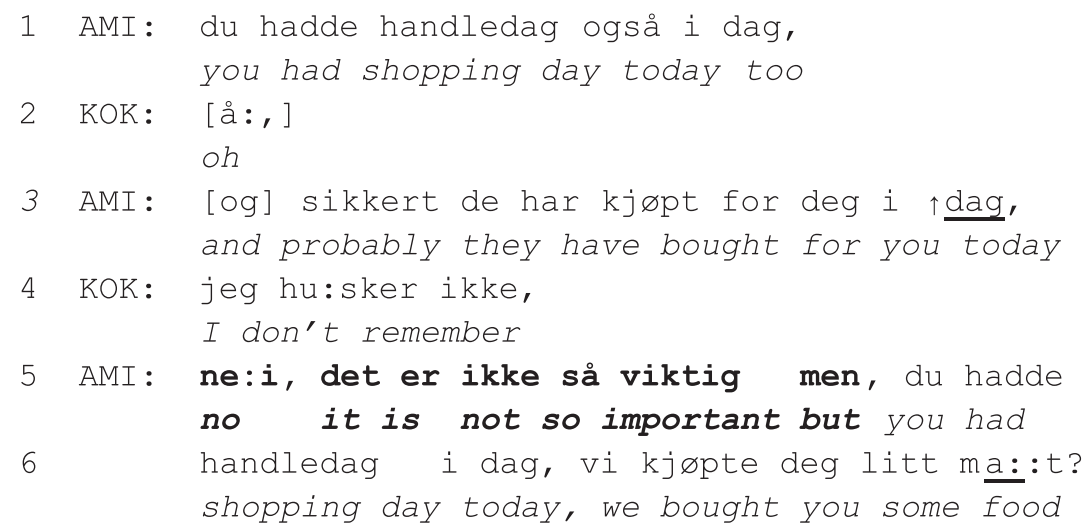

When Amina informs Koki that he has had "shopping day", Koki treats this as news by producing a change-ofstate token (Heritage 1984a). Amina consequently presents her conjecture about the tube in a way that does not appeal to Koki for confirmation, thus treating him as not knowledgeable about the event. Koki all the same treats it as seeking confirmation and states that he does not remember. At this point, Amina produces the account that it isn't so important, thus claiming that the lack of knowledge is not problematic. Instead of excusing his forgetfulness, she denies that it is problematic (the "pejorative quality" of the action, in Scott and Lyman's 1968 terms). This account is produced by the interlocutor and not the speaker, and serves to retrospectively redefine the import of her previous utterance as not having been intended to seek a confirmation from him.

In some cases, the persons with dementia do not seek to minimize or excuse their forgetfulness but instead expose or maximize it. As we shall see, this may also constitute a way of justifying their failure to provide personal information. Excerpt (6) is a case in point, drawn from a sequence in which the researcher (Jan) poses a factual question to the person with dementia, Veronica, about her age when she migrated to Norway:

\section{Excerpt (6) Veronica}

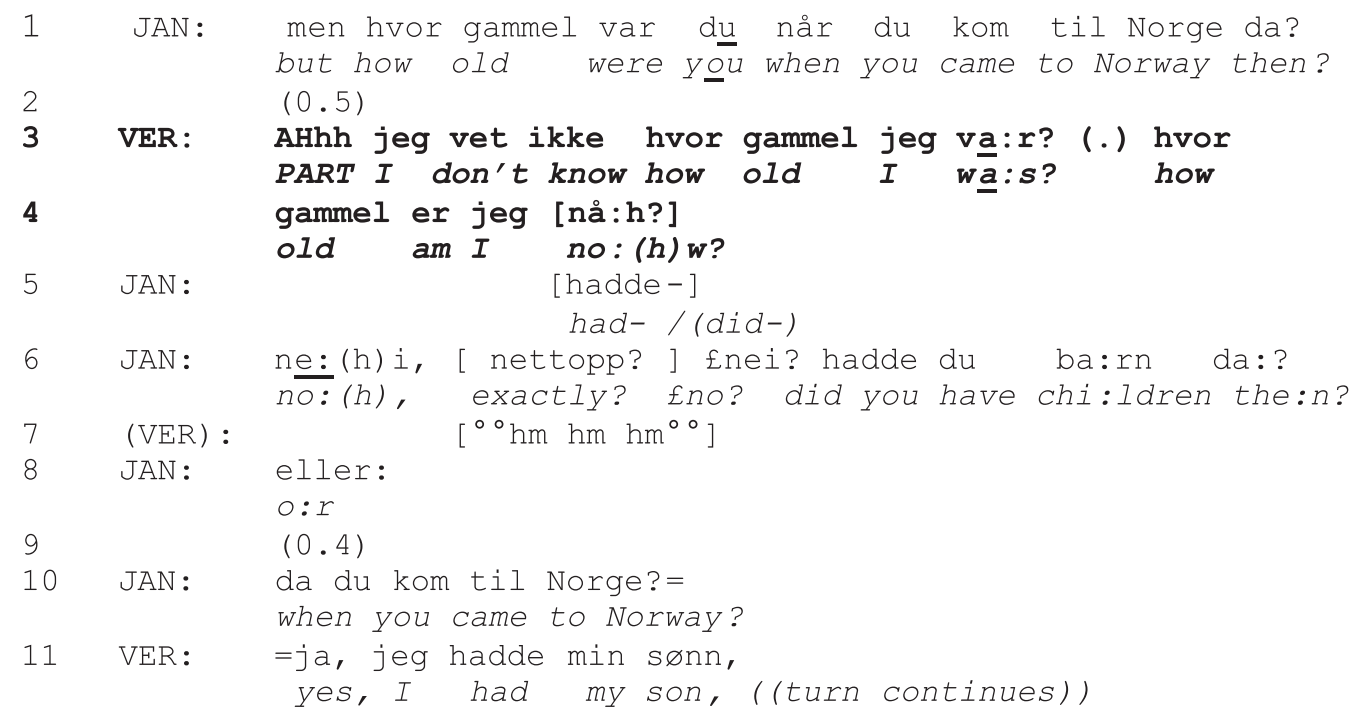

The question in line 1 enquires about a major event in Veronica's life, and it is designed in a way that presupposes that this information is accessible to her. Veronica's response in line 3 is delayed by a pause and starts with an emphatically produced "AHhh". This turn-initial interjection seems to function in much the 
same way as "oh" in English, which in this position after a question, according to Heritage (1998: 294), "can imply that a question was unexpected, unlooked for, or 'out of left field." Also the answer, which recycles the full clause from the question, seems to take some issue with the question, much like full clausal responses to wh-questions have been shown to do (Thompson et al. 2015). Furthermore, she continues her turn by posing a new question, that counters the original question by indicating that she does not even know how old she is now. The assertive (or 'rhetorical') character of this question is evident in that Jan responds by an acknowledgment ("no, right") (rather than, for example, an answer to the question). Veronica's question thus exposes and maximizes her forgetfulness rather than normalizing or downplaying it. The potential sensitivity of this self-deprecating response can be observed in Jan's interspersed laughter and smiley voice in the receipt ("ne:(h)i, nettopp? Łnei?"), and in her own soft laughter in line 7. Thus, the second part of the response, conveying that her lack of knowledge is even more fundamental than expected, may work as an account by indirectly presenting herself as a person with severe memory problems. And in light of this, her account also constitutes an implicit complaint about the question, implying that the interlocutor ought to have known that this would be an impossible question for her to answer (cf. Keevallik 2011, cited above). By exposing and maximizing her forgetfulness, she does not orient to her lack of knowledge as problematic but instead claims that it is the interlocutor's expectations which are problematic (Nilsson 2017). As such, the account constitutes a justification, denying or reducing the problematic character of her failure to answer the question.

\subsection{No-knowledge claims without accounts}

In some cases, persons with dementia claim not knowing or remembering without, however, accounting for their lack of knowledge. Excerpt (7) is a case in point. The person with dementia, Koki, is sitting with the researcher Pernille and looking at some of his favorite objects, which he keeps in a necklace and carries around with him most of the time. In the excerpt they are discussing a pocketknife.

\section{Excerpt (7) Koki}

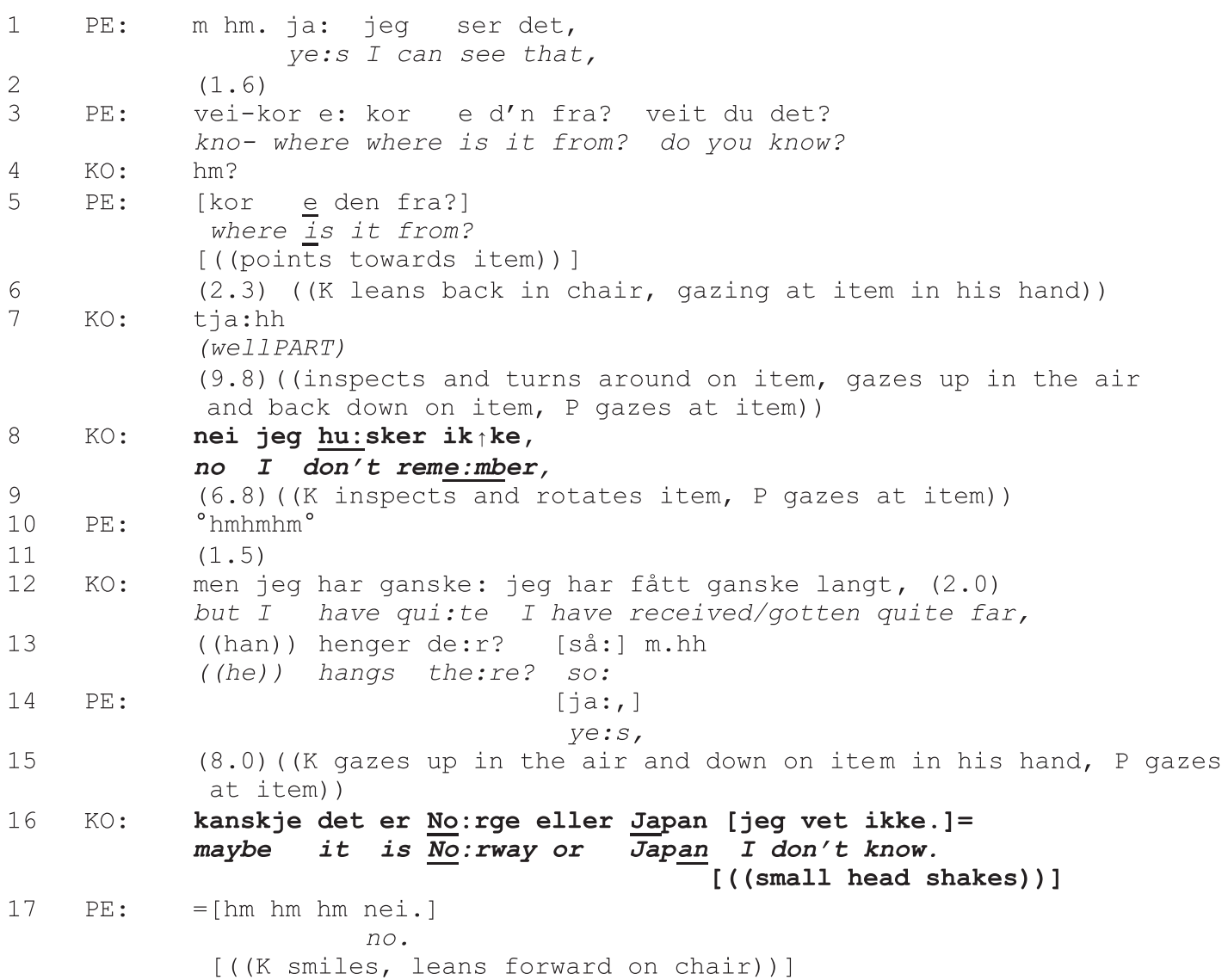


Pernille's enquiry in line 3 is incremented by a second question ("do you know?"), downgrading the expectation of epistemic access. Koki takes time to search for an answer, inspecting the object and just producing a place-holder (line 7), indicating that he is committing to providing a response. An even longer pause of 9.8 seconds ensues, in which he shifts between inspecting the object and looking up into the air, which can be considered a pose associated with 'searching' one's memory for something (Goodwin and Goodwin 1986). In line 8 , he renounces and produces a claim that he does not remember. This statement is not accounted for any further, but he may be considered as not giving up by the fact that he continues to inspect the object. After some more searching and what may perhaps be verbal memory cues (lines 12-13), he concludes the search activity by producing a partial answer in the form of a 'best guess'. Koki has been living his life partly in Japan and partly in Norway, so this guess is rather safe. The guess is marked as tentative by the adverb kanskje ('maybe') in line 16 and by the tag positioned marker "I don't know". The latter is not a literal claim of no epistemic access, but rather a hedge, reducing the epistemic authority of the previous statement (cf. Lindström et al. 2016, cited above). Anyhow, in this extract Koki puts in considerable time and effort to find an answer but ends up with a very tentative guess. Interestingly, he does not account for his lack of knowledge about the object, and neither does Pernille supply any excuses or justifications on his behalf, although her subtle laughter tokens in line 17 may orient to the delicateness of the incomplete answer. Furthermore, Koki does not display any signs of embarrassment or discomfort at not knowing. Thus, he does not seem to orient to the normative expectation that he ought to have access to this piece of information. In order to explain this rather deviant behavior, we might refer to his memory problems, which at this point are quite severe, as evidenced by his results on cognitive and linguistic tests. A possible interpretation of this behavior is that he has lost awareness of the social convention that the lack of this type of information is problematic and accountable. Such an explanation is in line with the findings in the longitudinal study by Hamilton (1994), which showed that as the Alzheimer's condition progressed, the person with dementia stopped providing accounts for missing answers and making reference to her memory problems (1994: 57).

\section{Conclusion}

The contribution of the current study is to describe and specify conversational practices used by persons with dementia and their interlocutors to account for the former's lack of knowledge in cases where personal information is made relevant and expectable at a specific point in a conversation. First, they may seek to normalize the lack of knowledge by claiming that it would be difficult for anyone to know or remember the information in question. Second, they may exceptionalize it by claiming that their cognitive or communicative impairment incidentally and temporarily disables them from accessing the information. Finally, they may justify their failure to provide information by claiming that it is not important, relevant or expectable that they should know. Such accounts dissociate the social character from the forgetfulness and thus constitute an attempt to avoid the loss of face associated with not remembering personal experiences.

The study shows that questions about personal experience may constitute a communicative challenge to persons with dementia. It may thus contribute to reflection among health care personnel and significant others on how questions about personal experience may create socially sensitive situations. As noted by Stickle (2015), the high frequency of “I don't know"-claims in persons with dementia may be related to the fact that the non-impaired interlocutors often take the role as 'interviewers'. Increased awareness of the social sensitivity of forgetfulness may thus guide practitioners to avoid conversational contributions that risk exposing the persons with dementia's lack of access to knowledge about personal experiences.

Acknowledgements: The authors are grateful to Maria Vonen for help with transcription and collection building. We have also profited from comments on the paper from Marianne Lind, Elin Nilsson, Heidi Hamilton and other members of the Dementia, Language, Interaction, and Cognition Network. This work was partly supported by the Research Council of Norway through its Centers of Excellence funding scheme, Norges Forskningsråd, Funder Id: 10.13039/501100005416, project number 223265. 


\section{References}

Deppermann, Arnulf. 2011. Constructions vs. lexical items as sources of complex meanings: a comparative study of constructions with German “verstehen”. In Peter Auer, Gesa von Essen, Werner Frick (eds.), Linguae \& Litterae, 88-126. Freiburg: De Gruyter.

Goffman, Erving. 1959. The presentation of self in everyday life. New York: Doubleday.

Goodwin, Charles. 1987. Forgetfulness as an interactive resource. Social Psychology Quarterly. 115-130.

Goodwin, Marjorie H. \& Charles Goodwin. 1986. Gesture and coparticipation in the activity of searching for a word. Semiotica 62. 51-76.

Guendozi, Jackie, \& Anna Pate. 2014. Interactional and cognitive resources in dementia: A perspective from Politeness Theory. In Robert W. Schrauf and Nicole Müller (eds.), Dialogue and dementia. Cognitive and communicative resources for engagement. New York: Psychology Press.

Hamilton, Heidi E. 1994. Conversations with an Alzheimer's patient: An interactional sociolinguistic study. Cambridge: Cambridge University Press.

Heritage, John. 1984a. A change-of-state token and aspects of its sequential placement. In J. Maxwell Atkinson \& John Heritage (eds.), Structures of social action, 299-345. Cambridge: Cambridge University Press.

Heritage, John. 1984b. Garfinkel and ethnomethodology. Cambridge: Polity Press.

Heritage, John. 1988. Explanations as accounts: A conversation analytic perspective. In Charles Antaki (ed.),Analyzing everyday explanation: A casebook of methods, 127-144. London: Sage.

Heritage, John. 1998. Oh-prefaced responses to inquiry. Language in Society 27. 291-334.

Heritage, John. 2011 Territories of knowledge, territories of experience: Empathic moments in interaction. In Tanya Stivers, Lorenza Mondada \& Jakob Steensig (eds.), The morality of knowledge in conversation, 159-183. Cambridge: Cambridge University Press.

Heritage, John. 2012. Epistemics in action: Action formation and territories of knowledge. Research on Language and Social Interaction 45.1-29.

Hutchby, lan. 2002. Resisting the incitement to talk in child counselling: Aspects of the utterance “I don't know". Discourse Studies 4. 147-68.

Keevallik, Leelo. 2011. The terms of not knowing. In Tanya Stivers, Lorenza Mondada and Jakob Steensig (eds.), The morality of knowledge in conversation. Cambridge: Cambridge University Press.

Keevallik, Leelo. 2016. Abandoning dead ends: The Estonian junction marker maitea ‘I don’t know'. Journal of Pragmatics 106. 115-128.

Laury, Ritva \& Marja-Liisa Helasvuo. 2016. Disclaiming epistemic access with 'know' and 'remember' in Finnish. Journal of Pragmatics 106. 80-96.

Lind, Marianne, Hanne G. Simonsen, Ingeborg S. Ribu, Bente A. Svendsen, Jan Svennevig \& Kees de Bot. 2018. Lexical access in a bilingual speaker with dementia: Changes over time. Clinical Linguistics \& Phonetics 32. 353-377.

Lindström, Jan, Yael Maschler \& Simona Pekarek Doehler. 2016. A cross-linguistic perspective on grammar and negative epistemics in talk-in-interaction. Journal of Pragmatics 106. 72-79.

Muntigl, Peter \& Kwok Tim Choi. 2010. Not remembering as a practical epistemic resource in couples therapy. Discourse Studies 12. 331-356.

Nilsson, Elin. 2017. Fishing for answers: Couples living with dementia managing trouble with recollection. Educational Gerontology 43. 73-88.

Pekarek Doehler, Simona. 2016. More than an epistemic hedge: French je sais pas 'I don't know' as a resource for the sequential organization of turns and actions. Journal of Pragmatics 106. 148-162.

Pomerantz, Anita. 1980. Telling my side:“Limited access' as a “fishing” device. Sociological Inquiry 50. 186-198.

Raymond, Geoffrey \& John Heritage. 2006. The epistemics of social relations: Owning grandchildren. Language in Society 35. 677-705.

Robinson, Jeffrey D. 2016. Accountability in social interaction. Oxford: Oxford University Press.

Sacks, Harvey. 1984. On doing 'being ordinary'. In J. M. Atkinson and J. Heritage (eds.), Structures of social action: studies in conversational analysis, 413-429. Cambridge, England: Cambridge University Press.

Schegloff, Emanuel A., \& Harvey Sacks. 1973. Opening up closings. Semiotica 8. 289-327.

Scott, Marvin B. \& Stanford M. Lyman. 1968. Accounts. American Sociological Review 33. 46-62.

Sidnell, Jack \& Tanya Stivers. 2013. The handbook of conversation analysis. Chichester: Wiley-Blackwell.

Stickle, Trini. 2015. Epistemic stance markers and the function of I don't know in the talk of persons with dementia and children with autism. Doctoral dissertation, The University of Wisconsin-Madison, ProQuest.

Stivers, Tanya, Lorenza Mondada \& Jakob Steensig (eds.). 2011. The morality of knowledge in conversation. Cambridge: Cambridge University Press.

Svennevig, Jan. 2013. Reformulation of questions with candidate answers. International Journal of Bilingualism 17. $189-204$.

Tao, Hongyin. 2016. Disputed memory and the social interactive functions of remembering/forgetting expressions in Mandarin conversation. Journal of Pragmatics 106. 184-202. 
Thompson, Sandra A., Barbara A. Fox \& Elizabeth Couper-Kuhlen. 2015. Grammar in everyday talk: Building responsive actions. Cambridge: Cambridge University Press.

Underwood, Kate. 2010. Interactive remembering: Insights into the communicative competence of older adults. Journal of Aging Studies 24. 145-166.

Weatherall, Ann. 2011. I don’t know as a prepositioned epistemic hedge. Research on Language and Social Interaction 44. 317-337. 